\title{
Molecular pathways involved in the improvement of non-alcoholic fatty liver disease
}

\author{
Gilberto Paz-Filho, ${ }^{1, *}$, Claudio Alberto Mastronardi ${ }^{1, *}$, Brian J Parker ${ }^{2}$, Ainy Khan', \\ Antonio Inserra', Klaus I Matthaei ${ }^{3}$, Monika Ehrhart-Bornstein ${ }^{4}$, Stefan Bornstein ${ }^{4}$, \\ Ma-Li Wong ${ }^{1,+}$ and Julio Licinio ${ }^{+}$
}

Departments of ${ }^{1}$ Translational Medicine ${ }^{2}$ Genome Biology ${ }^{3}$ Molecular Bioscience, The John Curtin School of Medical Research, The Australian National University, Garran Road, Building 131, Acton, Canberra, Australian Capital Territory 0200, Australia

${ }^{4}$ Medical Clinic III, Carl Gustav Carus University Hospital, Dresden University of Technology, Fetscherstraße 74, 01307 Dresden, Germany

*(G Paz-Filho and C A Mastronardi contributed equally and should be considered co-first authors)

${ }^{\dagger}$ (M-L Wong and J Licinio are now at the Mind and Brain Theme, South Australian Health and Medical Research Institute, and Department of Psychiatry, School of Medicine, Flinders University, PO Box 11060, Adelaide, SA 5001, Australia.)

Correspondence should be addressed to M-L Wong

Email mali.wong@sahmri.com

\begin{abstract}
Non-alcoholic fatty liver disease (NAFLD) and non-alcoholic steatohepatitis are components of the metabolic syndrome. Serum leptin levels are elevated in obesity, but the role of leptin in the pathophysiology of the liver involvement is still unclear. To identify the effects and mechanisms by which leptin influences the pathogenesis of NAFLD, we performed epididymal white adipose tissue (eWAT) transplantation from congenic wild-type mice into the subcutaneous dorsal area of $L e p^{o b / o b}$ recipient mice and compared the results with those of the Lep ${ }^{o b / o b}$ sham-operated mice. The mice were followed for 102-216 days. During killing, the transplanted mice had significantly lost body weight and exhibited significantly higher leptin levels, improved glucose tolerance, and lower liver injury scores than the shamoperated mice. Liver microarray analysis showed that novel pathways related to GA-binding protein (GABP) transcription factor targets, pheromone binding, and olfactory signaling were differentially expressed in the transplanted mice. Our data also replicate pathways known to be involved in NAFLD, such as those involved in the regulation of microRNAs, lipid, glucose, and glutathione metabolism, peroxisome proliferator-activated receptor signaling, cellular regulation, carboxylic acid processes, iron, heme, and tetrapyrrole binding, immunity and inflammation, insulin signaling, cytochrome P450 function, and cancer. Conclusion: wild-type eWAT transplantation into $L e p^{o b / o b}$ mice led to improvements in metabolism, body weight, and liver injury, possibly attributed to the production of leptin by the transplanted eWAT. These improvements were accompanied by the differential expression of novel pathways. The causal relationship between GABP downregulation and NAFLD improvement remains to be determined.
\end{abstract}

\section{Key Words}

- adipose tissue

- leptin

- liver

- microarray
Journal of Molecular Endocrinology (2013) 51, 167-179 http://jme.endocrinology-journals.org DOI: 10.1530/JME-13-0072
() 2013 Society for Endocrinology Printed in Great Britain
Published by Bioscientifica Ltd 


\section{Introduction}

The prevalence of obesity and insulin resistance (IR) is increasing worldwide: over 78 million Americans are obese, and one-third have high IR (Yanovski \& Yanovski 2011). These factors have impacted the prevalence of nonalcoholic fatty liver disease (NAFLD), the most common form of chronic liver dysfunction in developed countries. While NAFLD could be considered a component of the metabolic syndrome, the liver involvement includes a spectrum ranging from simple steatosis (NAFLD) to non-alcoholic steatohepatitis (NASH) and cirrhosis (Neuschwander-Tetri \& Caldwell 2003).

Approximately $23 \%$ of patients with NAFLD progress to NASH (Wong et al. 2010), which is histologically characterized by steatosis, lobular inflammation, hepatocellular ballooning, and fibrosis (Kleiner et al. 2005). The mechanisms leading to NASH are poorly understood; the 'two-hit' hypothesis is a simple mechanistic explanation and has recently been modified to encompass a 'multiplehit' hypothesis (Tilg \& Moschen 2010). The 'first-hit' hypothesis is now considered to be related to the development of obesity and IR; these promote deposition of lipids in the hepatic parenchyma, causing a cellular stress response. According to the 'multiple-hit' hypothesis, NAFLD progression is due to the combined effects of a variety of insults, including direct hepatocyte lipotoxicity, oxidative and endoplasmic reticulum stress, and cytokine release. As a consequence, hepatocellular injury activates immune system-mediated necrotic and apoptotic cell death pathways (Malhi et al. 2006). Emerging views also question this NAFLD/NASH continuum and propose that these two entities may be independent, but akin conditions (Yilmaz 2012) because only a minority of liver steatosis cases progress to NASH, and NASH and NAFLD may be genetically distinct entities (Kawaguchi et al. 2012).

The absence of leptin, the adipokine produced mainly by white adipose tissue (WAT), is implicated in the pathogenesis of NASH in cases of lipodystrophy syndromes. Leptin therapy leads to significant reductions in steatosis, liver enzyme levels, and hepatocellular injury in human lipodystrophy (Javor et al. 2005, Simha et al. 2012). The leptin-deficient $\left(L e p^{o b / o b}\right)$ mouse is a useful animal model of NAFLD, with severe obesity, hepatic steatosis, and IR. However, it does not spontaneously progress to steatohepatitis, requiring a second hit to trigger this progression (Faggioni et al. 1999). Lep ${ }^{o b / o b}$ mice have limited hepatic fibrosis capacity due to the suppression of innate and acquired immune responses, resulting in the depletion of natural killer T-cells and defective tumor growth factor $\beta$-dependent genes, such as pro-collagen type 1 (Leclercq et al. 2002). In Lep ${ }^{o b / o b}$ mice, short-term leptin treatment may not correct hepatocyte dysfunction and steatosis (Leclercq et al. 2006). Although WAT transplantation was effective for the treatment and prevention of obesity, as well as of endocrine/metabolic alterations associated with leptin deficiency, it exerted profound effects on multiple physiological functions in $L e p^{o b / o b}$ mice: reduced body weight gain and IR and restored fertility (Klebanov et al. 2005, Sennello et al. 2006, Barros et al. 2009, Pereira et al. 2011). However, the assessment of NAFLD progression after WAT transplantation has not been evaluated yet.

In the current study, we transplanted congenic epididymal WAT (eWAT) to test whether leptin-producing eWAT influences the course of NAFLD in $L e p^{o b / o b}$ mice. Furthermore, we characterized the liver gene expression profile and molecular pathways that accompanied these changes and employed computational enrichment analyses to direct follow-up experimental analysis.

\section{Materials and methods}

\section{Animals}

All animal procedures were performed under the established guidelines of humane care and use of animals and approved by the Australian National University Animal Experimentation Ethics Committee. All mice were fed standard chow and water ad libitum and housed in a facility that maintained a $12 \mathrm{~h}$ light: $12 \mathrm{~h}$ darkness cycle and stressand pathogen-free conditions. Heterozygous B6.V-Lep ${ }^{o b} / \mathrm{J}$ mice (Jackson Laboratory, Bar-Harbor, ME, USA) were bred with NZeg.EGFP (enhanced green fluorescent protein) transgenic mice to produce congenic $\mathrm{NZegTg}^{+} \mathrm{Lep}^{+/+}$ (donors, referred here as $\mathrm{Lep}^{+/+}$) and $\mathrm{NZegTg}^{-} \mathrm{Lep}^{o b / o b}$ (leptin-deficient recipients, referred as $L e p^{o b / o b}$ ) mice. The B6.V-Lep ${ }^{o b} / \mathrm{J}$ strain was backcrossed to the C57BL/6J background for more than 30 generations. The NZeg.EGFP strain on a C57BL/ 6 background is phenotypically normal, except for its intense fluorescence as it expresses a nuclear EGFP under a ubiquitous promoter (pCAGG) at very high levels in all cells (K Matthaei (2013), unpublished).

\section{eWAT transplantation procedure}

Seven- to twelve-week-old $L e p^{o b / o b}$ mice were either sham-operated ( $n=9$, six males) or transplanted

Published by Bioscientifica Ltd 
( $n=12$, five males), under sterile conditions with eWAT harvested from multiple lean $\mathrm{Lep}^{+/+}$donors (two to four donors/recipients were used in order to transplant $2.0 \mathrm{~g}$ of eWAT for each recipient); eWAT was cut into small pieces and immediately loaded in a syringe through the plunger end, so that warm ischemia time was $<10 \mathrm{~min}$ (Klebanov et al. 2005). Lep ${ }^{o b / o b}$ recipients were anesthetized with $100 \mathrm{mg} / \mathrm{kg}$ ketamine and $10 \mathrm{mg} / \mathrm{kg}$ xylazine intraperitoneally. Their dorsal region was shaved, and a $0.5 \mathrm{~cm}$ skin incision was made, followed by the creation of a small subcutaneous pouch in which $0.5-2.0 \mathrm{~g}$ of donor $\mathrm{Lep}^{+/+}$eWAT were transferred with the help of a 16-gauge needle to minimize adipocyte damage during injection. Buprenorphine $(0.5 \mathrm{mg} / \mathrm{kg}$ i.p.) was given before and after surgery. The sham-operated mice underwent the same surgical procedure and treatment, but no eWAT was transplanted. We transplanted eWAT from congenic mice to minimize the risk of rejection, and no immunosuppressive drugs were administered. To monitor rejection, the mice were frequently evaluated employing a structured score sheet assessing animal recovery. Weight was monitored weekly post-operatively for 150-200 days, followed by killing with truncal blood and tissue collection. The transplanted and sham-operated mice had access to the same diet.

\section{Plasma hormone/metabolite measurements}

Circulating leptin levels were determined at the end point using ELISA kits in duplicate (R\&D systems, Minneapolis, $\mathrm{MN}$, USA). Insulin levels were determined using an ultrasensitive ELISA (Alpco, Salem, NH, USA).

Intraperitoneal glucose tolerance test (IPGTT) was performed before killing. The mice were injected with a solution of $250 \mathrm{mg}$ glucose/kg i.p. after $5 \mathrm{~h}$ of fasting. Blood was collected from the tail vein at $0,15,30$, and $60 \mathrm{~min}$ after glucose injection. A standard glucometer (Accutrend, Roche Diagnostics) was used to measure blood glucose levels.

\section{Histology}

Liver samples from each mouse were fixed in a $4 \%$ formaldehyde solution for $24 \mathrm{~h}$ and embedded in paraffin wax. Sections of $4 \mu \mathrm{m}$ were cut and stained using standard protocols for hematoxylin and eosin and Masson Trichrome staining and observed using a Leica Stereo (1.210) microscope (Leica, Mannheim, Germany).

\section{4'-6-Diamidino-2-phenylindole staining for EGFP cells}

EGFP-expressing cells were identified by 4'-6-diamidino-2phenylindole (DAPI) staining of the liver, spleen, and lung tissues. Small fresh tissue samples were extracted from the transplanted and sham-operated mice, embedded in $15 \times 15 \times 5 \mathrm{~mm}$ cryomolds (Sakura Finetek, Torrance, CA, USA), and immersed in a cooling bath of acetone and dry ice. Tissue samples were embedded in the optimum cutting temperature compound (Sakura Finetek) and cut using a cryostat at $-20{ }^{\circ} \mathrm{C}$ to obtain $4-6 \mu \mathrm{m}$ cryosections on thin glass slides. Frozen sections were then air-dried for $1 \mathrm{~h}$. For fixing of the slides, the slide racks were placed in pre-cooled acetone and fixed for $15 \mathrm{~min}$. The slides were air-dried for $1 \mathrm{~h}$ and wrapped in an aluminum foil. For DAPI staining, the sections were rehydrated with PBS for $15 \mathrm{~min}$ and treated with DAPI solution diluted to $300 \mathrm{nM}$ (Millipore, Billerica, MA, USA) for $15-20 \mathrm{~min}$ at room temperature. The slides were rinsed with PBS, and VECTASHIELD Mounting Medium (Vector Laboratories, Burlingame, CA, USA) was used to prevent the rapid loss of fluorescence during microscopic examination. The slides were then mounted with cover slips and sealed with nail polish. The expression of EGFP-expressing cells in the liver, spleen, and lung sections of the transplanted and sham-operated mice was examined under a Leica TCS SP5 confocal microscope. The microscope was set at the laser setting of $405 \mathrm{~mm}$ for DAPI staining and $488 \mathrm{~mm}$ for GFP with $400 \mathrm{~Hz}$ scan speed.

\section{Histological scoring}

Liver sections were scored following the scoring system described by Kleiner et al. (2005), excluding the last item ('diagnostic classification'). This scoring system was complemented by the addition of macrovesicular steatosis grading (Sanyal 2002; Supplementary Table 1, see section on supplementary data given at the end of this article). Scoring was blinded (performed by G P-F and revised by M-L W).

\section{RNA extraction}

Liver samples were dissected, snap-frozen in liquid nitrogen, and stored at $-80^{\circ} \mathrm{C}$. Total RNA was extracted using the RNeasy Lipid Mini Kit including optional DNase digestion (Qiagen) and quantified using a Nanodrop ND-100 spectrophotometer (Thermo-Fisher Scientific, Scoresby, VIC, Australia), and its quality was assessed by a Nano-Chip assay (Agilent 2100 Bioanalyzer, Life Sciences Chemical Analysis, Foster City, CA, USA).

Published by Bioscientifica Ltd. 


\section{Quality control of RNA and microarray samples}

The same amount of high-quality RNA from each of the samples was used for the transplanted and sham-operated groups. The assessment of RNA integrity on the Agilent Bioanalyzer 2100 indicated an average RNA integrity number of 9.5; thus, RNA samples provided for the microarray were of high quality. No samples were identified as biological or technical outliers; thus, all samples were included in the subsequent bioinformatic analysis. A gene expression profile was completed for the liver samples of the transplanted $(n=3)$ and sham-operated $(n=3) L e p^{o b / o b}$ mice.

\section{Gene expression microarray}

Microarray services were provided by the ACFR Biomolecular Resource Facility, Australian National University. All protocols were conducted as described in the Affymetrix GeneChip Expression Analysis Technical Manual. All samples selected for our microarray studies were obtained from male mice of a similar age at the time of the surgical procedure ( $n=3$ shams, $79.3 \pm 24.3$ days old; $n=3$ transplanted mice, $79.7 \pm 24.0$ days old; $P=0.984)$. During killing, body weights of the sham-operated mice were significantly higher than that at day 0 (D0). By contrast, the transplanted mice had lower weights during killing, when compared with their weights at D0. Supplementary Tables 2 and 3, see section on supplementary data given at the end of this article, summarize data on the samples utilized for microarray.

Briefly, $100 \mathrm{ng}$ of total RNA were reverse-transcribed, and cDNA was fragmented and biotinylated by terminal transferase and labeled. Three micrograms of labeled cDNA were added to probe the GeneChip Mouse Gene 1.0 ST Array (Affymetrix). All reactions were performed in biological triplicates and technical triplicates to minimize the effects of technical variability on true biological variability; we selected three age-matched male mice from each group.

\section{Quantitative real-time reverse transcriptase PCR (RT-PCR)}

A subset of differentially expressed genes was verified using RT-PCR, using liver samples from all the studied mice (nine sham-operated and 12 transplanted mice). Two micrograms of total RNA were reverse-transcribed to cDNA using the OMNISCRIPT RT kit (Qiagen) and oligodt primers (Invitrogen). Primers for each gene of interest were exon spanning, designed using the Primer Express
Software (Applied Biosystems); amplicon lengths were between 57 and 169 bp (Supplementary Table 4, see section on supplementary data given at the end of this article). A standard curve of pooled, serially diluted cDNA was run for each gene and for housekeeping genes using the 7900HT Fast RT-PCR System (Applied Biosystems). cDNA samples were diluted between 1:20 and 1:200 and run in triplicate for both the gene of interest and housekeeping genes (Gapdh and Rplp4). All primer sets were tested for optimal dissociation curves with amplification efficiencies between 85 and 100\%. The three SYBR cycle threshold values were averaged for each sample, and the RNA input for the curve was calculated from the standard curve. To check for the possibility of genomic contamination, we included a minus-reverse transcriptase control for each sample in a RT-PCR experiment run for the housekeeping gene Gapdh (primers targeted to the same exon). Fold changes (FCs) were expressed as a ratio of Rplp4 expression for each sample.

\section{Statistical analysis}

Data are expressed as means \pm s.e.M. The Mann-Whitney $U$ non-parametric test or Student's $t$-test was used when appropriate for comparison between the groups, using GraphPad Prism 5.00 (GraphPad Software, Inc., La Jolla, CA, USA), and differences were considered significant if $P \leq 0.05$. Pearson correlation analyses were also performed.

\section{Microarray data analysis}

Data files (.cel) were generated using default settings for scaling and detection call parameters in the GeneChip Operating Software (Affymetrix). Expression microarrays were normalized by quantile normalization and robust multi-array average summarization per gene (Stratowa 2011) with non-specific filtering of low variance genes (removed genes with an interquartile range (IQR) $<0.25$ of overall IQR across the arrays). FCs were expressed in LogFC. LogFC and $P$ values were computed by moderated $t$-statistic (using the Limma $\mathrm{R}$ package, Smyth (2005)). The $P$ values were adjusted for false discovery rate (FDR; Benjamini \& Hochberg 1995). Differentially expressed genes were ranked by the adjusted $P$ values, and genes with an adjusted $P$ value $\leq 0.05$ were considered as differentially expressed genes at a statistically significant level. Only those genes were used for GO analyses.

Published by Bioscientifica Ltd. 
(a)

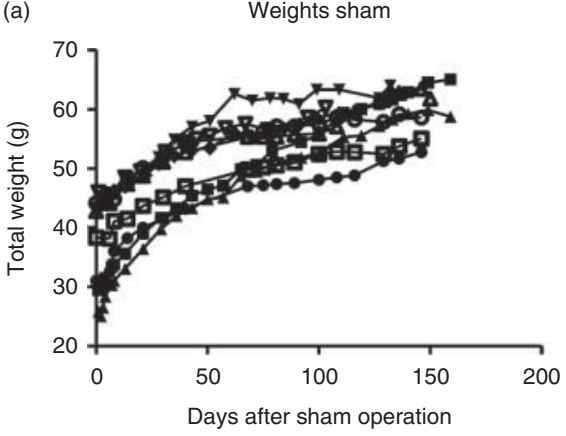

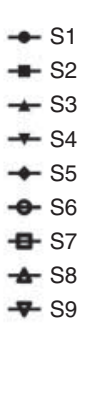

(b) Weights transplanted

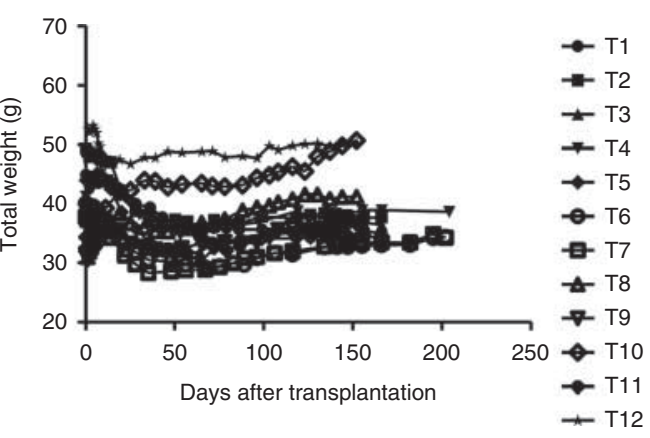

(c)

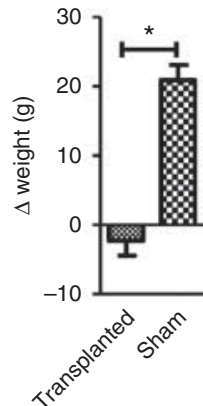

\section{Figure 1}

Weight changes after sham operation and transplantation. Absolute individual weight changes after sham operation (a) and transplantation (b). (c) Differences between weights 136 days after transplantation or sham operation. $* P<0.001$.

\section{Enrichment analysis}

Several programs were used to further analyze the lists of differentially expressed genes generated, with the significance level and FC settings mentioned above, to place them in a functional context. Enrichment analysis was performed using GoMiner. Differentially expressed genes were entered into GoMiner, which uses data in the Gene Ontology (GO) database (www.geneontology.org) to identify GO groups that are significantly overrepresented in gene lists. A cut-off $P \leq 0.05$ was selected for GO categories. Significant GO groups containing only one differentially expressed gene were disregarded to reduce the likelihood of false positives. Gene set enrichment analysis (Subramanian et al. 2005) was performed based on ranking by $\operatorname{LogFC}$, using the digitally available $\mathrm{R} /$ Bioconductor (Luo et al. 2009).

Gene sets used were defined using the following resources: i) gene sets from Molecular Signature Database (MSigDB) v 3.0 (Liberzon et al. 2011), including miRNA and transcription factor (TF) target motif set gene sets as defined by Xie et al. (2005) and ii) GO (Ashburner et al. 2000) based on GO terms (gene_ontology_edit.obo, downloaded 1/25/2008) and their associations with human genes (gene2go, downloaded 1/22/2008). Only associations with the following evidence codes are included in the MSigDB gene sets: IDA IPI, IMP IGI, IEP ISS, and TAS.

Pathway analysis gene sets were obtained from BioCarta (www.biocarta.com), KEGG (www.genome.jp/kegg), and Reactome (www.reactome.org). Enrichment analyses were performed separately for FCs in one direction or two directions. Neighborhood gene sets were as defined by Subramanian et al. (2005): starting with a curated list of 380 cancer-associated genes (Brentani et al. 2003), and four expression compendium datasets (National Cancer
Institute 2010, Ramaswamy et al. 2001, Su et al. 2001, 2004) were used to find gene neighborhoods with $\geq 25$ genes at a Pearson's correlation threshold of 0.8 (427 sets). A TF gene set was defined from Fulton et al. (2009). We also summarized gene set enrichments of the following specific pathways: sterol and fatty acid pathways, insulindependent regulation and sensitivity to insulin pathways, and immune/inflammatory mediator pathways. Pathways with an adjusted $P$ value $\leq 0.10$ were considered to be significantly differentially expressed.

\section{Results}

\section{eWAT transplantation}

eWAT transplantation led to significant weight loss in the $L e p^{o b / o b}$ mice. During killing, the transplanted group had lost $1.84 \pm 2.27 \mathrm{~g}$ and the sham-operated group had gained $21.44 \pm 2.41 \mathrm{~g}$ of body weight $(P<0.0001)$. The weight differences between D136 and D0 were $-2.32 \pm 2.14$ and

Table 1 Summary of body weight, liver histology, and serum biochemical results

\begin{tabular}{|c|c|c|c|}
\hline Data & $\begin{array}{l}\text { Transplanted } \\
\qquad(n=12)\end{array}$ & $\begin{array}{c}\text { Sham- } \\
\text { operated } \\
(n=9)\end{array}$ & P value \\
\hline Male:female & $5: 7$ & $6: 3$ & 0.256 \\
\hline Liver score & $5.5 \pm 0.4$ & $9.9 \pm 1.1$ & 0.0004 \\
\hline Insulin (pmol/dl) & $4.08 \pm 1.51$ & $156.90 \pm 33.16$ & $<0.0001$ \\
\hline Leptin (pg/ml) & $365.7 \pm 39.6$ & $239.4 \pm 14.2$ & 0.01 \\
\hline$\Delta$ Weight (g; final-D0) & $-1.84 \pm 2.27$ & $+21.44 \pm 2.41$ & $<0.0001$ \\
\hline$\Delta$ Weight (g; D136-D0) & $-2.32 \pm 2.14$ & $+20.92 \pm 2.16$ & $<0.0001$ \\
\hline $\begin{array}{l}\text { AUC glucose } \\
\qquad(\mathrm{mmol} / \mathrm{l} \times 60 \mathrm{~min})\end{array}$ & $34.41 \pm 1.53$ & $40.04 \pm 2.33$ & $<0.05$ \\
\hline
\end{tabular}

AUC, area under the curve.

Published by Bioscientifica Ltd. 

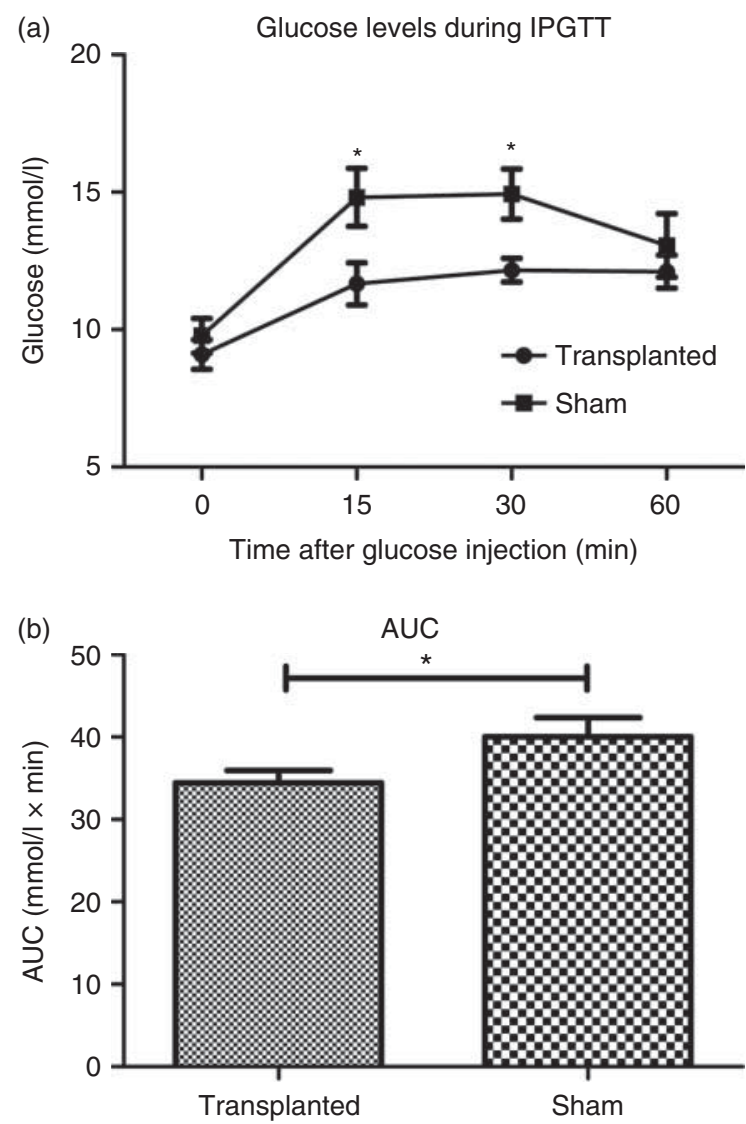

Figure 2

Changes in glucose tolerance after sham operation and transplantation. Glucose levels during IPGTT performed during killing (a). Area under the curve (AUC) for glucose (b). ${ }^{*} P<0.05$.

$+20.92 \pm 2.16 \mathrm{~g}$ for the transplanted and sham-operated mice respectively $(P<0.0001$; Fig. 1$)$. No signs of rejection or inflammatory processes were observed after the transplantation procedure or sham operation.

\section{Plasma hormone and metabolite measurements}

Leptin levels were measured in seven mice of each group. The transplanted mice had significantly higher levels than the sham-operated mice $(365.7 \pm 39.6$ and $239.4 \pm 14.2 \mathrm{pg} / \mathrm{ml}$ respectively; $P=0.01$; Table 1 ).

During killing, non-fasting plasma insulin levels were significantly lower in the transplanted group $(n=12 ; 4.08 \pm 1.51 \mathrm{pmol} / \mathrm{dl})$ than in the sham-operated group ( $n=9 ; 156.90 \pm 33.16 \mathrm{pmol} / \mathrm{l} ; P<0.0001)$. eWAT transplantation improved glucose sensitivity: the area under the curve for glucose measured during the IPGTT was significantly lower in the transplanted group $(34.43 \pm 1.53 \mathrm{mmol} / \mathrm{l} \times 60 \mathrm{~min})$ than in the sham-operated group ( $40.04 \pm 2.33 \mathrm{mmol} / 1 \times 60 \mathrm{~min}, P=0.04$; Fig. 2).

\section{Liver histology}

Transplantation of eWAT from the $\mathrm{Lep}^{+/+}$donors improved liver histology. The histology of the shamoperated $L e p^{o b / o b}$ mice was similar to that of the nonoperated $L e p^{o b / o b}$ mice (data not given), with micro- and macrovesicular steatosis, mild hepatocyte inflammation, few Mallory bodies, and mild fibrosis (Fig. 3A and B). Liver steatosis was improved in the eWAT-transplanted $L e p^{o b / o b}$ mice; their liver samples exhibited primarily microvesicular steatosis, very few/no macrovesicules, no visible injured hepatocytes (Fig. 3C), and few Mallory bodies (Fig. 3D). The liver injury score was significantly lower in the transplanted group $(5.5 \pm 0.4)$ than in the sham-operated group $(9.9 \pm 1.1 ; P=0.0004)$. Table 1 summarizes the scores, hormone levels, glucose levels, and weights; individual values are given in Supplementary Tables 2 and 3. EGFP-expressing cells were identified in the sections of liver, spleen, and lung tissues of the transplanted mice (Supplementary Figures 1, 2 and 3, see section on supplementary data given at the end of this article).

\section{Differential gene expression analysis}

A total of 119 unique genes (significance-adjusted $P<0.05$ ) were differentially expressed, by moderated $t$-test (Supplementary Table 5, see section on supplementary data given at the end of this article).
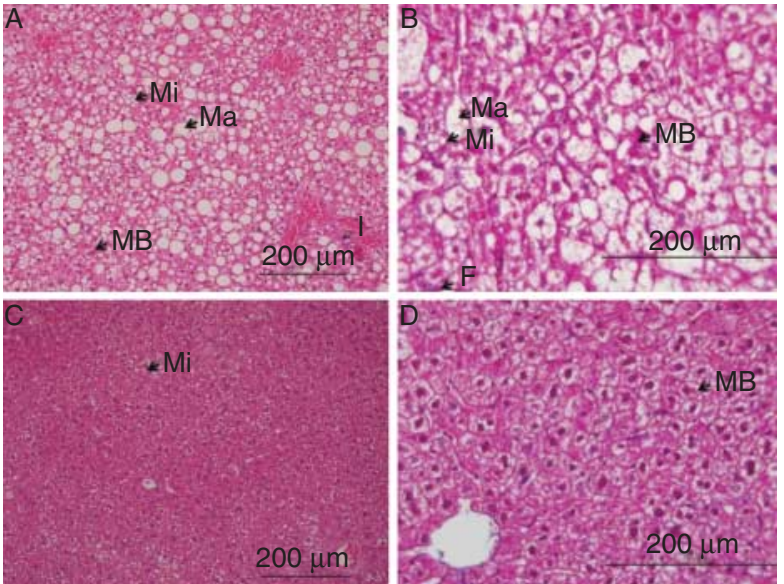

\section{Figure 3}

Liver histology of the sham-operated $(A$ and $B)$ and transplanted ( $C$ and $D)$ mice. (A and C) Hematoxylin and eosin, 200 X; (B and D) Masson Trichrome, $400 \times . \mathrm{Ma}$, macrovesicular steatosis; MB, Mallory bodies; Mi, microvesicular steatosis; F, fibrosis; I, inflammation.

Published by Bioscientifica Ltd. 


\section{Pathway analyses}

Enrichment analyses showed that several pathways were differentially expressed in the same direction (either down- or upregulated). The pathways that were significantly upregulated (Adjusted $P$ value $<0.10$ ) in the same direction included i) pathways involving cation channel activity and ii) pathways related to olfactory signaling/transduction, odorant binding, and pheromone binding/response/receptor activity (Table 2).

Some of the pathways that were significantly downregulated (Adjusted $P$ value $<0.10$ ) were related to i) TF targets related to the GA-binding protein (GABP) motif and to miR-124A; ii) metabolic processes such as the biosynthesis of unsaturated fatty acids (FA) and sphingolipid,

Table 2 Downregulated and upregulated pathways on enrichment analyses. Only essential gene sets are included

\section{Analysis}

KEGG

Motif

GO

KEGG and Reactome
Pathway

Cell cycle

Ubiquitin-mediated proteolysis

Chronic myeloid leukemia

Biosynthesis of unsaturated fatty acids

Glutathione metabolism

Regulation of actin cytoskeleton

Glycerolipid metabolism

Toll-like receptor signaling pathway

Limonene and pinene degradation

DNA replication

P53 signaling pathway

MGGAAGTG_V\$GABP_B (motifs corresponding

to the transcription factor GABP)

TGCCTTA, MIR-124A (microRNA mir-124A)

Intracellular transport

Endosome

Vacuole

Cell cycle process

Cytosol

Lipid binding

Protein folding

Reactome cell cycle mitotic

KEGG lysosome

KEGG leishmania infection

Reactome membrane trafficking

KEGG glycerolipid metabolism

KEGG natural killer cell-mediated cytotoxicity

KEGG p53 signaling pathway

KEGG glutathione metabolism

KEGG vibrio cholerae infection

KEGG amino sugar and nucleotide sugar metabolism

BioCarta G2 pathway

KEGG biosynthesis of unsaturated fatty acids

KEGG endocytosis

BioCarta p53 hypoxia pathway

Reactome sema4d in semaphorin signaling

KEGG sphingolipid metabolism

KEGG $n$ glycan biosynthesis

GO essential gene sets

GO non-essential gene sets

Cation channel activity

Odorant binding

Response to pheromone

Pheromone binding

Pheromone receptor activity

Reactome olfactory signaling pathway

KEGG and Reactome essential gene sets

KEGG and Reactome non-essential gene sets
KEGG olfactory transduction

\begin{tabular}{|c|c|c|}
\hline Mean FCs & $\begin{array}{c}\text { Unadjusted } \\
P \text { value }\end{array}$ & $\begin{array}{l}\text { Adjusted } \\
P \text { value }\end{array}$ \\
\hline-4.04 & $3.7 \times 10^{-5}$ & 0.0063 \\
\hline-3.02 & $1.4 \times 10^{-3}$ & 0.0873 \\
\hline-3.01 & $1.5 \times 10^{-3}$ & 0.0873 \\
\hline-2.99 & $2.1 \times 10^{-3}$ & 0.0891 \\
\hline-2.78 & $3.4 \times 10^{-3}$ & 0.0928 \\
\hline-2.67 & $4.0 \times 10^{-3}$ & 0.0928 \\
\hline-2.66 & $4.5 \times 10^{-3}$ & 0.0928 \\
\hline-2.62 & $4.7 \times 10^{-3}$ & 0.0928 \\
\hline-2.76 & $5.0 \times 10^{-3}$ & 0.0928 \\
\hline-2.61 & $5.6 \times 10^{-3}$ & 0.0938 \\
\hline-2.53 & $6.4 \times 10^{-3}$ & 0.0981 \\
\hline-4.67 & $1.6 \times 10^{-6}$ & 0.001 \\
\hline-4.01 & $3.2 \times 10^{-5}$ & 0.0127 \\
\hline-5.24 & $1.0 \times 10^{-7}$ & 0.0002 \\
\hline-4.45 & $5.7 \times 10^{-6}$ & 0.006 \\
\hline-4.31 & $1.1 \times 10^{-5}$ & 0.006 \\
\hline-4.23 & $1.0 \times 10^{-5}$ & 0.006 \\
\hline-3.69 & $1.2 \times 10^{-4}$ & 0.0209 \\
\hline-3.02 & $1.3 \times 10^{-3}$ & 0.0986 \\
\hline-3.02 & $1.4 \times 10^{-3}$ & 0.0986 \\
\hline-5.58 & $1.9 \times 10^{-8}$ & $1.53 \times 10^{-5}$ \\
\hline-4.37 & $9.5 \times 10^{-6}$ & $3.84 \times 10^{-3}$ \\
\hline-3.62 & $2.1 \times 10^{-4}$ & $1.73 \times 10^{-2}$ \\
\hline-3.33 & $5.4 \times 10^{-4}$ & $3.49 \times 10^{-2}$ \\
\hline-2.96 & $2.0 \times 10^{-3}$ & $6.00 \times 10^{-2}$ \\
\hline-2.86 & $2.4 \times 10^{-3}$ & $6.58 \times 10^{-2}$ \\
\hline-2.81 & $2.9 \times 10^{-3}$ & $6.94 \times 10^{-2}$ \\
\hline-2.83 & $3.1 \times 10^{-3}$ & $7.07 \times 10^{-2}$ \\
\hline-2.67 & $4.5 \times 10^{-3}$ & $7.98 \times 10^{-2}$ \\
\hline-2.56 & $6.1 \times 10^{-3}$ & $9.39 \times 10^{-2}$ \\
\hline-2.61 & $6.4 \times 10^{-3}$ & $9.39 \times 10^{-2}$ \\
\hline-2.58 & $7.2 \times 10^{-3}$ & $9.47 \times 10^{-2}$ \\
\hline-2.44 & $7.6 \times 10^{-3}$ & $9.47 \times 10^{-2}$ \\
\hline-2.57 & $7.6 \times 10^{-3}$ & $9.47 \times 10^{-2}$ \\
\hline-2.49 & $7.8 \times 10^{-3}$ & $9.48 \times 10^{-2}$ \\
\hline-2.44 & $8.5 \times 10^{-3}$ & $9.83 \times 10^{-2}$ \\
\hline-2.42 & $8.9 \times 10^{-3}$ & $9.90 \times 10^{-2}$ \\
\hline+4.09 & $2.6 \times 10^{-5}$ & 0.0571 \\
\hline+3.96 & $6.0 \times 10^{-5}$ & 0.0571 \\
\hline+3.88 & $8.3 \times 10^{-5}$ & 0.0571 \\
\hline+3.91 & $7.4 \times 10^{-5}$ & 0.0571 \\
\hline+3.80 & $1.1 \times 10^{-4}$ & 0.0626 \\
\hline+6.39 & $2.8 \times 10^{-10}$ & $2.25 \times 10^{-7}$ \\
\hline+5.60 & $1.9 \times 10^{-8}$ & $7.55 \times 10^{-6}$ \\
\hline
\end{tabular}

http://jme.endocrinology-journals.org DOI: 10.1530/JME-13-0072
(C) 2013 Society for Endocrinology Printed in Great Britain 
glutathione, and glycerolipid metabolism; iii) cellular processes such as cell cycle, intracellular transport, lysosome, DNA replication, p53 signaling, and ubiquitinmediated proteolysis; iv) cancer gene sets; and v) immune/ inflammatory processes and mediators such as toll-like receptor signaling pathway and natural killer cellmediated toxicity (Table 2).

We also identified pathways that were differentially expressed whereby members of a gene set could be either up- or downregulated, but not necessarily in the same direction, such as i) drug and xenobiotic metabolism by cytochrome P450; ii) PPAR signaling pathway; iii) retinol, arachidonic/organic acid, and monocarboxylic acid metabolic processes; iv) heme, pyrrole, and iron binding; v) inflammatory response and immune system signaling; vi) monooxygenase, electron carrier, and oxidoreductase activities; vii) cell fractions; viii) cancer gene sets; ix) lipid/lipoprotein metabolism; and $\mathrm{x}$ ) biological oxidations (Table 3 ).

Gene set enrichments of specific pathways involved in the pathophysiology of NAFLD showed the significant downregulation in the same direction (Adjusted $P$ value $<0.10)$ of the following pathways: i) motifs corresponding to the GABP TF; ii) miR-124A; and iii) glucose regulation of insulin secretion. No pathway was significantly upregulated in the same direction. The following pathways were differentially expressed in either direction (Adjusted $P$ value $<0.10$ ): i) metabolism of lipids/lipoproteins; ii) monocarboxylic acid metabolic process; iii) glutathione metabolism; iv) PPAR signaling pathway; and v) immune system signaling and inflammatory/ defense responses (Table 4; full enrichment analyses summarized in Supplementary Table 6, see section on supplementary data given at the end of this article).

Table 3 Differentially expressed pathway analyses in which gene expression changes were not necessarily in the same direction. Cancer gene sets included are given in the supplementary tables

\begin{tabular}{|c|c|c|}
\hline Analysis & Pathway & Mean FCs \\
\hline \multirow[t]{3}{*}{ KEGG essential gene sets } & Drug metabolism by cytochrome P450 & 3.79 \\
\hline & Glutathione metabolism & 3.39 \\
\hline & PPAR signaling pathway & 2.77 \\
\hline \multirow[t]{3}{*}{ KEGG non-essential gene sets } & Metabolism of xenobiotics by cytochrome P450 & 3.34 \\
\hline & Retinol metabolism & 3.23 \\
\hline & Arachidonic acid metabolism & 3.21 \\
\hline \multirow[t]{3}{*}{ GO essential gene sets } & Cell fraction & 5.01 \\
\hline & Monocarboxylic acid metabolic process & 3.89 \\
\hline & Inflammatory response & 3.62 \\
\hline \multirow[t]{16}{*}{ GO non-essential gene sets } & Insoluble fraction & 4.96 \\
\hline & Membrane fraction & 4.93 \\
\hline & Microsome & 4.11 \\
\hline & Vesicular fraction & 4.09 \\
\hline & Monooxygenase activity & 4.11 \\
\hline & Electron carrier activity & 3.94 \\
\hline & $\begin{array}{l}\text { Oxidoreductase activity, acting on paired donors, with } \\
\text { incorporation or reduction of molecular oxygen }\end{array}$ & 3.77 \\
\hline & Carboxylic acid metabolic process & 3.60 \\
\hline & Organic acid metabolic process & 3.59 \\
\hline & Response to wounding & 3.57 \\
\hline & Defense response & 3.56 \\
\hline & Iron ion binding & 3.55 \\
\hline & Cellular alcohol metabolic process & 3.52 \\
\hline & Lipid biosynthetic process & 3.42 \\
\hline & Heme binding & 3.31 \\
\hline & Tetrapyrrole binding & 3.31 \\
\hline \multirow[t]{2}{*}{ Cell lines essential } & Reactome metabolism of lipids and lipoproteins & 4.54 \\
\hline & Reactome signaling in immune system & 3.41 \\
\hline \multirow[t]{2}{*}{ Cell lines non-essential } & Reactome biological oxidations & 3.72 \\
\hline & KEGG drug metabolism by cytochrome P450 & 3.50 \\
\hline
\end{tabular}

\begin{tabular}{l}
$\begin{array}{c}\text { Unadjusted } \\
\text { P value }\end{array}$ \\
\hline $1.4 \times 10^{-4}$ \\
$6.0 \times 10^{-4}$ \\
$3.3 \times 10^{-3}$ \\
$7.0 \times 10^{-4}$ \\
$1.0 \times 10^{-3}$ \\
$1.0 \times 10^{-3}$ \\
$3.6 \times 10^{-7}$ \\
$6.0 \times 10^{-5}$ \\
$1.7 \times 10^{-4}$ \\
$4.76 \times 10^{-7}$ \\
$5.57 \times 10^{-7}$ \\
$3.07 \times 10^{-5}$ \\
$3.27 \times 10^{-5}$ \\
$3.49 \times 10^{-5}$ \\
$5.62 \times 10^{-5}$ \\
$1.20 \times 10^{-4}$ \\
\\
$1.73 \times 10^{-4}$ \\
$1.74 \times 10^{-4}$ \\
$1.92 \times 10^{-4}$ \\
$2.01 \times 10^{-4}$ \\
$2.16 \times 10^{-4}$ \\
$2.39 \times 10^{-4}$ \\
$3.51 \times 10^{-4}$ \\
$6.38 \times 10^{-4}$ \\
$6.38 \times 10^{-4}$ \\
$4.0 \times 10^{-6}$ \\
$3.5 \times 10^{-4}$ \\
0.0001 \\
0.0004 \\
\end{tabular}

\begin{tabular}{l} 
Adjusted \\
$\boldsymbol{P}$ value \\
\hline 0.0249 \\
0.0331 \\
0.0944 \\
0.0331 \\
0.0331 \\
0.0331 \\
0.0005 \\
0.0205 \\
0.0394 \\
0.0005 \\
0.0005 \\
0.0160 \\
0.0160 \\
0.0160 \\
0.0205 \\
0.0365 \\
0.0394 \\
0.0394 \\
0.0394 \\
0.0394 \\
0.0395 \\
0.0409 \\
0.0567 \\
0.0921 \\
0.0921 \\
0.0032 \\
0.0823 \\
0.0613 \\
0.0823 \\
\end{tabular}

FDR, false discovery rate.

http://jme.endocrinology-journals.org DOI: 10.1530/JME-13-0072
C 2013 Society for Endocrinology Printed in Great Britain
Published by Bioscientifica Ltd 
Table 4 Gene set enrichments of sterol and fatty acid pathways, insulin-dependent regulation and sensitivity to insulin pathways, and immune/inflammatory mediator pathways

\begin{tabular}{|c|c|c|c|c|}
\hline Analysis & Pathway & Mean FCs & $\begin{array}{l}\text { Unadjusted } \\
P \text { value }\end{array}$ & $\begin{array}{l}\text { Adjusted } \\
P \text { value }\end{array}$ \\
\hline \multicolumn{5}{|c|}{ Sterol and fatty acid pathways } \\
\hline \multirow[t]{2}{*}{ KEGG } & Biosynthesis of unsaturated fatty acids & -3.0 & $2.1 \times 10^{-3}$ & 0.0891 \\
\hline & Fatty acid metabolism ${ }^{a}$ & 2.2 & 0.0160 & 0.2111 \\
\hline \multirow[t]{2}{*}{ Cell lines } & Reactome metabolism of lipids and lipoproteins & -2.0 & $2.1 \times 10^{-2}$ & 0.1353 \\
\hline & Reactome metabolism of lipids and lipoproteins ${ }^{a}$ & 4.5 & $4.0 \times 10^{-6}$ & 0.0032 \\
\hline \multirow[t]{2}{*}{ GO } & Monocarboxylic acid metabolic process ${ }^{a}$ & 3.9 & $6.0 \times 10^{-5}$ & 0.0205 \\
\hline & Fatty acid metabolic process ${ }^{a}$ & 3.2 & $7.5 \times 10^{-4}$ & 0.1024 \\
\hline \multicolumn{5}{|c|}{$\begin{array}{l}\text { Insulin-dependent regulation } \\
\text { and sensitivity to insulin }\end{array}$} \\
\hline \multirow[t]{4}{*}{ Motif } & $\begin{array}{l}\text { MGGAAGTG_V\$GABP_B (motifs corresponding } \\
\text { to the transcription factor GABP) }\end{array}$ & -4.7 & $1.6 \times 10^{-6}$ & 0.0012 \\
\hline & TGCCTTA, MIR-124A (microRNA mir-124A) & -4.0 & $3.2 \times 10^{-5}$ & 0.0127 \\
\hline & ACCAAAG, MIR-9 & -3.1 & $9.6 \times 10^{-4}$ & 0.1270 \\
\hline & $\begin{array}{l}\text { GCACTTT, MIR-17-5P, MIR-20A, MIR-106A, MIR-106B, } \\
\text { MIR-20B, MIR-519D }\end{array}$ & -3.2 & $6.3 \times 10^{-4}$ & 0.1270 \\
\hline \multirow[t]{4}{*}{ KEGG } & Insulin signaling pathway ${ }^{a}$ & -2.1 & $1.8 \times 10^{-2}$ & 0.1307 \\
\hline & Glutathione metabolisma & 3.4 & 0.0006 & 0.0331 \\
\hline & PPAR signaling pathway ${ }^{a}$ & 2.8 & 0.0034 & 0.0944 \\
\hline & Glycolysis/gluconeogenesis $^{a}$ & 2.2 & 0.0137 & 0.2111 \\
\hline Reactome & Reactome glucose regulation of insulin secretion & -2.2 & $1.5 \times 10^{-2}$ & 0.1232 \\
\hline GO & Glycolysis/gluconeogenesis & -1.8 & $4.0 \times 10^{-2}$ & 0.1588 \\
\hline \multicolumn{5}{|c|}{ Immune/inflammatory mediators } \\
\hline Reactome & Reactome signaling in immune system ${ }^{a}$ & 3.4 & $3.5 \times 10^{-4}$ & 0.0823 \\
\hline \multirow[t]{3}{*}{$\mathrm{GO}$} & Inflammatory response ${ }^{a}$ & 3.6 & $1.7 \times 10^{-4}$ & 0.0394 \\
\hline & Defense response ${ }^{a}$ & 3.5 & $2.0 \times 10^{-4}$ & 0.0394 \\
\hline & Acute inflammatory response ${ }^{a}$ & 3.2 & $9.2 \times 10^{-4}$ & 0.1093 \\
\hline
\end{tabular}

aPathways that were differentially expressed whereby members of a gene set could be either up- or downregulated, not necessarily in the same direction.

\section{RT-PCR}

We confirmed the differential expression of 25 selected genes using RT-PCR (Table 5).

\section{Discussion}

NAFLD is a common complication of obesity and the metabolic syndrome and currently represents the most common form of chronic liver dysfunction. The pathogenesis of NAFLD and its progression to NASH are still not completely clear, and leptin is known to play a role (Garg \& Misra 2002). In this study, the transplantation of perigonadal adipose tissue from leptin-sufficient mice into $o b / o b$ mice led to increased serum leptin levels, significant weight loss, decreased insulin and glucose levels, and improvement of liver injury scores after 102-216 days of follow-up. Moreover, we observed that these changes were accompanied with the expected differential expression of pathways already known to be involved in liver metabolism and/or leptin function and of novel pathways related to GABP TF, pheromone binding, and olfactory signaling, the biological significance of which in NAFLD pathogenesis remains to be determined.

Currently, treatments aimed at ameliorating liver diseases should be limited to those with NASH, as patients with NAFLD without steatohepatitis have excellent prognosis from a liver standpoint (Chalasani et al. 2012). Treatment options include lifestyle intervention and use of insulin-sensitizing agents (such as metformin and pioglitazone) and the antioxidant vitamin E. Other therapies may be considered on individual bases or need further evaluation (Chalasani et al. 2012). To our knowledge, this is the first study to evaluate the effects of adipose tissue transplantation on leptin deficiency-associated NAFLD. Previous studies have described the effects of the procedure on parameters other than histological ones (Klebanov et al. 2005, Sennello et al. 2006, Barros et al. 2009). In our study, transplantation of leptin-secreting WAT led to weight loss, increased leptin levels, decreased insulin levels, and decreased IR, in concordance with previous studies. It was also an efficacious therapy for ameliorating NAFLD: sham-operated mice had significantly higher liver injury scores. Macrovesicular steatosis

Published by Bioscientifica Ltd. 
Table 5 Genes differentially expressed by microarray and confirmed by RT-PCR. Liver samples from nine sham-operated and 12 transplanted mice were used for the RT-PCR experiment

\begin{tabular}{|c|c|c|c|}
\hline Pathway & $\begin{array}{l}\text { Confirmed } \\
\text { genes }\end{array}$ & FCs & $P$ value \\
\hline \multirow{2}{*}{$\begin{array}{l}\text { Drug metabolism } \\
\text { cytochrome P450 }\end{array}$} & Cyp2b9 & -1.9558 & 0.033 \\
\hline & Cyp2c54 & 2.7124 & 0.001 \\
\hline \multirow[t]{5}{*}{ Glutathione metabolism } & Gstm3 & -3.8226 & 0.0005 \\
\hline & Gpx6 & 5.0516 & 0.003 \\
\hline & Gpx4 & -1.4507 & 0.0415 \\
\hline & Gsta1 & -2.5128 & 0.0225 \\
\hline & Gstp2 & 3.8300 & 0.0089 \\
\hline \multirow[t]{3}{*}{ PPAR signaling pathway } & Pparg & -1.6606 & 0.0018 \\
\hline & $C d 36$ & -1.9234 & 0.0005 \\
\hline & Fabp5 & 3.2580 & 0.0024 \\
\hline \multirow{5}{*}{$\begin{array}{l}\text { Reactome biological } \\
\text { oxidation pathway }\end{array}$} & Cyp7b1 & 11.0988 & 0.0012 \\
\hline & Cyp39a1 & -2.1529 & $<0.0001$ \\
\hline & Сур2u1 & 4.6404 & 0.0223 \\
\hline & Сур4f14 & 3.5690 & $<0.00001$ \\
\hline & Сур17а1 & -2.1795 & 0.0106 \\
\hline \multirow[t]{3}{*}{ KEGG drug metabolism } & Mgst3 & -2.2831 & $<0.0001$ \\
\hline & Ugt2b1 & 1.8220 & 0.0348 \\
\hline & Adh4 & 2.1911 & 0.0001 \\
\hline \multirow[t]{2}{*}{ GABP } & Tfrc & -2.0855 & $<0.0001$ \\
\hline & Rarb & -1.6229 & 0.0003 \\
\hline \multirow[t]{3}{*}{ MiR-124A } & $\operatorname{Scd} 2$ & -8.0906 & 0.0003 \\
\hline & Anxa5 & -1.8316 & 0.0336 \\
\hline & $A b c c 4$ & -3.1400 & 0.0005 \\
\hline \multirow[t]{3}{*}{ Glucose metabolism } & Airn (iso- & -3.2089 & 0.0009 \\
\hline & $\begin{array}{l}\text { forms } 1 / 4 \text {, } \\
2 \text { and } 3 \text { ) }\end{array}$ & $\begin{array}{c}\text { to } \\
-1.3998\end{array}$ & $\begin{array}{l}\text { to } \\
0.0013\end{array}$ \\
\hline & lgfbp2 & 6.2809 & 0.0057 \\
\hline
\end{tabular}

was absent in only $22 \%$ of the sham-operated mice, whereas it was absent in $83 \%$ of the transplanted mice. Mild fibrosis was observed in a very small fraction of mice, including non-transplanted ones, possibly because leptin is an essential mediator of hepatic fibrosis in response to chronic liver injury (Leclercq et al. 2002). Similarly, only a mild degree of inflammation was observed in a few sham-operated mice, possibly due to the absence of the proinflammatory and fibrogenic effects of leptin. The introduction of leptin did not increase fibrosis/ inflammation because it was followed by weight loss and a decrease in IR.

\section{Novel pathways involved in NAFLD}

We identified the differential expression of pathways that may play a role in the pathogenesis of NAFLD: pathways involving motifs corresponding to GABP TF targets and olfactory and pheromone physiology. To our knowledge, this is the first study to show the differential expression of GABP TF targets associated with NAFLD improvement. GABP is the only obligate multimeric TF of the Ets family, intimately involved in critical cellular functions, including cell cycle control, cytoprotection, T-cell development, protein synthesis, cellular metabolism, embryogenesis, cellular differentiation, apoptosis, and carcinogenesis. It binds to DNA sequences that are rich in guanine and adenine and controls gene expression in several important biological settings (Rosmarin et al. 2004). It also regulates essential housekeeping genes important for cellular energy metabolism and ATP generation, including genes that control mitochondrial biogenesis and function.

In the liver, the GABP maybe a key regulator of mitochondrial function, detoxification, and antioxidative stress systems (Rosmarin et al. 2004), which are critical in ameliorating oxidative stress in different liver diseases. Loss of GABP exacerbates animal models of NASH (Chowdhry et al. 2010) by causing mitochondrial dysfunction, associated with the upregulation of cell death pathways via reactive oxygen species (ROS) and $\mathrm{Ca}^{2+}$ signaling (Pessayre 2007). In this setting, mitochondrial biogenesis is increased as a compensatory mechanism. By stimulating mitochondrial function and ameliorating oxidative stress, GABP activation could be a potential target for NASH treatment and prevention.

On the other hand, there is also evidence suggesting that lower GABP expression could also result in positive outcomes for metabolic functions. GABP deficiency may protect against diet-induced weight gain, obesity, and glucose intolerance; GABP also impairs adipogenesis, as it decreases adipose tissue mass and adipocyte size (Zhang et al. 2012) and modulates hepatic lipid homeostasis (Huang et al. 2010). Therefore, GABP downregulation could have improved insulin sensitivity and directly decreased fatty acid content of hepatic triacylglycerols of the eWAT-transplanted $L e p^{o b / o b}$ mice. The higher GABP TF targets expression levels found in leptin-deficient mice that were sham-operated could also contribute to explaining why this mouse strain has relatively modest fibrosis and a benign NAFLD progression course, as it does not spontaneously progress to steatohepatitis.

Our study showed that eWAT transplantation in leptin-deficient mice ameliorated liver injury and downregulated hepatic GABP TF targets. It is unclear if the observed GABP TF targets downregulation in the transplanted mice was the cause of this mentioned amelioration or its effect. For instance, as a cause, leptin could have directly downregulated hepatic GABP TF targets expression, decreasing the fatty acid content of hepatic triacylglycerols and improving liver injury. As an effect, better metabolic performance could have decreased ROS and cell death, decreasing the compensatory

Published by Bioscientifica Ltd. 
mitochondrial biogenesis. Mitochondrial biogenesis can be indirectly assessed by the expression levels of PPAR- $\gamma$ coactivator-1- $\alpha$ (PGC-1- $\alpha$ ), a transcriptional coactivator of GABP, which was not differently expressed in our study; therefore, we do not have enough data to support that mitochondrial biogenesis was affected by eWAT transplantation.

Pathways related to olfactory signaling/transduction, odorant binding, and pheromone binding/response/ receptor activity were significantly upregulated in the transplanted mice. The relationship between the liver and pheromones is poorly defined, but it is known that the synthesis and release of pheromones are regulated by major urinary proteins (MUPs), synthesized in the liver (Tirindelli et al. 2009). It is possible that leptin had an effect on the synthesis of MUPs, determining the release of pheromones and the differential expression of pathways involving olfactory/pheromone physiology. Moreover, the reversal of the leptin-deficient state restores eugonadism and fertility, stimulating the synthesis and secretion of pheromones. However, it is possible that the upregulation of these pathways has no biological significance, since olfactory pathways are often differentially and non-specifically expressed due to the fact that mammals have a myriad of olfactory genes. In our study, these pathways are so intensely enriched that we cannot discard the hypothesis of these findings having true biological significance.

\section{Known pathways relevant to NAFLD}

We identified the differential expression of several pathways that are related to liver function and/or physiological processes that are related to the actions of leptin. These pathways are related to processes such as PPAR function, glutathione, insulin, and lipid/lipoprotein metabolism, immune system, cancer and p53 signaling, inflammatory and defense responses, and the cell cycle. Moreover, microRNA pathways were downregulated. Their expression is altered in the livers of NASH and NAFLD patients (Cermelli et al. 2011, Wang et al. 2012) and has also been implicated in the prevention/ suppression of hepatocarcinogenesis via modulation of inflammatory signaling and induction of tumor-specific apoptosis (Hatziapostolou et al. 2011). It is unclear whether miR downregulation is an effect of decreased cell proliferation and apoptosis. In our study, cytochrome P450 pathways were upregulated, which could lead to a leptin-mediated improvement of liver injury, by decreasing the accumulation of polyunsaturated FAs (Gonzalez et al. 2011). We observed a significant downregulation in the pathway related to the biosynthesis of unsaturated FAs, but our study design does not allow us to determine whether this was a direct effect of CYP450 upregulation.

The analysis of the differentially expressed genes showed the downregulation of many genes associated with a proinflammatory state, such as Cxcl10, Fabp4, and Tlr12. In comparison with a previous study where exogenous leptin was administered for 12 days, only Cyp17a1 features among the top downregulated genes with FC being $>2$ in both studies (Sharma et al. 2010). In concordance with the study of Sharma et al., Gck was downregulated, which is associated with decreased lipogenesis and decreased IR. Furthermore, Igfbp2 was overexpressed in both studies, which has been associated with leptin-mediated decreased IR (Wheatcroft et al. 2007). These observations strengthen the hypothesis that the results obtained from a third group of leptin-treated animals would have been different from the results obtained from the WAT-transplanted mice. Nevertheless, future studies should compare the effects of chronic leptin administration.

In our study, although the transplanted mice had significantly higher leptin levels than the sham-operated mice, their serum leptin levels were less than one-tenth of the levels observed in WT mice. The procedure resulted in improvements in phenotype regardless of the low leptin levels, but it is unclear whether different results would have been observed had leptin levels reached normal levels. These improvements are likely to be attributed to the production of leptin by the transplanted eWAT, but the effect of other adipokines, such as adiponectin, cannot be ruled out. Also, the transplantation site might play a role in the phenotypic changes: intra-abdominal transplantation of small amounts of epididymal adipose tissue (100-150 mg) had significantly improved glucose tolerance when transplanted to areas close to the hepatic artery (Foster et al. 2011), with opposite results being observed when transplanted to areas with portal venous drainage (Rytka et al. 2011). In one study comparing the origin and the transplantation site, leptin-sufficient mice transplanted with visceral fat into the subcutaneous area did not lose weight, but further comparisons with animals submitted to transplantation into the visceral cavity were not pursued by the authors (Tran et al. 2008).

We studied a relatively small and heterogeneous sample, with three biological replicates for each condition (transplanted and sham-operated), which is typical and adequate for exploratory expression analyses. Donor mice that expressed nuclear EGFP were used, aiming at

Published by Bioscientifica Ltd. 
localizing donor cells in the recipients. We found EGFP-expressing cells in the livers, spleens, and lungs of recipient mice (Supplementary Figures 1, 2 and 3); the nature of these cells was not determined, but our results indicate that these cells were producing leptin or other factors that were alleviating the symptoms of leptin deficiency. We hypothesize that WAT transplantation reduced systemic inflammation (corroborated by the observation that several inflammatory/immune pathways were downregulated in the non-essential gene set pathway analysis), leading to decreased hypoxia and hepatocyte injury and improving mitochondrial function. As a consequence, GABP TF targets expression was decreased. Further studies need to confirm the findings on GABP expression and to provide additional information on its role, such as chromatin immunoprecipitation sequencing, western blotting, and immunohistochemistry, to assess changes in the protein level and to locate the related genes. By establishing the causal relationship between GABP and NAFLD, GABP can become useful as a biomarker of liver injury improvement or as a therapeutic tool against hepatic steatosis.

\section{Supplementary data}

This is linked to the online version of the paper at http://dx.doi.org/10.1530/ JME-13-0072.

\section{Declaration of interest}

The authors declare that there is no conflict of interest that could be perceived as prejudicing the impartiality of the research reported.

\section{Funding}

This work was supported by The Australian National University, by the Australian Department of Innovation, Industry, Science, and Research International Science Linkages Project EF100011, and by the German-Australian Institute for Translational Medicine.

\section{Acknowledgements}

The authors thank Llara Weaver, Aulikki Koskinen, and Yeping Cai for their technical support and Anne Prins for her assistance in the preparation of the tissue samples for histological analyses.

\section{References}

Ashburner M, Ball CA, Blake JA, Botstein D, Butler H, Cherry JM, Davis AP, Dolinski K, Dwight SS, Eppig JT et al. 2000 Gene ontology: tool for the unification of biology. The Gene Ontology Consortium. Nature Genetics 25 25-29. (doi:10.1038/75556)

Barros CC, Almeida SS, Mori MA, Valero VB, Haro AS, Batista EC, Rosa TS, Bacurau RF, Wurtele M \& Araujo RC 2009 Efficient method for obtaining Lep(ob)/Lep(ob)-derived animal models using adipose tissue transplantations. International Journal of Obesity 33 938-944. (doi:10.1038/ijo.2009.95)

Benjamini Y \& Hochberg Y 1995 Controlling the false discovery rate: a practical and powerful approach to multiple testing. Journal of the Royal Statistical Society. Series B $\mathbf{5 7} 289-300$.

Brentani H, Caballero OL, Camargo AA, da Silva AM, da Silva WA Jr, Dias Neto E, Grivet M, Gruber A, Guimaraes PE, Hide W et al. 2003 The generation and utilization of a cancer-oriented representation of the human transcriptome by using expressed sequence tags. PNAS $\mathbf{1 0 0}$ 13418-13423. (doi:10.1073/pnas.1233632100)

Cermelli S, Ruggieri A, Marrero JA, Ioannou GN \& Beretta L 2011 Circulating microRNAs in patients with chronic hepatitis $\mathrm{C}$ and non-alcoholic fatty liver disease. PLoS ONE 6 e23937. (doi:10.1371/ journal.pone.0023937)

Chalasani N, Younossi Z, Lavine JE, Diehl AM, Brunt EM, Cusi K, Charlton M \& Sanyal AJ 2012 The diagnosis and management of non-alcoholic fatty liver disease: practice guideline by the American Association for the Study of Liver Diseases, American College of Gastroenterology, and the American Gastroenterological Association. Hepatology 55 2005-2023. (doi:10.1002/hep.25762)

Chowdhry S, Nazmy MH, Meakin PJ, Dinkova-Kostova AT, Walsh SV, Tsujita T, Dillon JF, Ashford ML \& Hayes JD 2010 Loss of Nrf2 markedly exacerbates nonalcoholic steatohepatitis. Free Radical Biology \& Medicine 48 357-371. (doi:10.1016/j.freeradbiomed.2009.11.007)

Faggioni R, Fantuzzi G, Gabay C, Moser A, Dinarello CA, Feingold KR \& Grunfeld C 1999 Leptin deficiency enhances sensitivity to endotoxininduced lethality. American Journal of Physiology 276 R136-R142.

Foster MT, Shi H, Softic S, Kohli R, Seeley RJ \& Woods SC 2011 Transplantation of non-visceral fat to the visceral cavity improves glucose tolerance in mice: investigation of hepatic lipids and insulin sensitivity. Diabetologia 54 2890-2899. (doi:10.1007/ s00125-011-2259-5)

Fulton DL, Sundararajan S, Badis G, Hughes TR, Wasserman WW, Roach JC $\&$ Sladek R 2009 TFCat: the curated catalog of mouse and human transcription factors. Genome Biology 10 R29. (doi:10.1186/gb-200910-3-r29)

Garg A \& Misra A 2002 Hepatic steatosis, insulin resistance, and adipose tissue disorders. Journal of Clinical Endocrinology and Metabolism $\mathbf{8 7}$ 3019-3022. (doi:10.1210/jc.87.7.3019)

Gonzalez M, Sealls W, Jesch ED, Brosnan MJ, Ladunga I, Ding X, Black PN \& DiRusso CC 2011 Defining a relationship between dietary fatty acids and the cytochrome P450 system in a mouse model of fatty liver disease. Physiological Genomics 43 121-135. (doi:10.1152/physiolgenomics.00209.2010)

Hatziapostolou M, Polytarchou C, Aggelidou E, Drakaki A, Poultsides GA, Jaeger SA, Ogata H, Karin M, Struhl K, Hadzopoulou-Cladaras M et al. 2011 An HNF4 $\alpha$-miRNA inflammatory feedback circuit regulates hepatocellular oncogenesis. Cell 147 1233-1247. (doi:10.1016/j.cell. 2011.10.043)

Huang J, Tabbi-Anneni I, Gunda V \& Wang L 2010 Transcription factor Nrf2 regulates SHP and lipogenic gene expression in hepatic lipid metabolism. American Journal of Physiology. Gastrointestinal and Liver Physiology 299 G1211-G1221. (doi:10.1152/ajpgi.00322.2010)

Javor ED, Ghany MG, Cochran EK, Oral EA, DePaoli AM, Premkumar A, Kleiner DE \& Gorden P 2005 Leptin reverses nonalcoholic steatohepatitis in patients with severe lipodystrophy. Hepatology 41 753-760. (doi:10.1002/hep.20672)

Kawaguchi T, Sumida Y, Umemura A, Matsuo K, Takahashi M, Takamura T, Yasui K, Saibara T, Hashimoto E, Kawanaka M et al. 2012 Genetic polymorphisms of the human PNPLA3 gene are strongly associated with severity of non-alcoholic fatty liver disease in Japanese. PLOS ONE 7 e38322. (doi:10.1371/journal.pone.0038322)

Klebanov S, Astle CM, DeSimone O, Ablamunits V \& Harrison DE 2005 Adipose tissue transplantation protects ob/ob mice from obesity, 
normalizes insulin sensitivity and restores fertility. Journal of Endocrinology 186 203-211. (doi:10.1677/joe.1.06150)

Kleiner DE, Brunt EM, Van Natta M, Behling C, Contos MJ, Cummings OW, Ferrell LD, Liu YC, Torbenson MS, Unalp-Arida A et al. 2005 Design and validation of a histological scoring system for nonalcoholic fatty liver disease. Hepatology 41 1313-1321. (doi:10.1002/hep.20701)

Leclercq IA, Farrell GC, Schriemer R \& Robertson GR 2002 Leptin is essential for the hepatic fibrogenic response to chronic liver injury. Journal of Hepatology 37 206-213. (doi:10.1016/S01688278(02)00102-2)

Leclercq IA, Vansteenberghe M, Lebrun VB, VanHul NK, Abarca-Quinones J, Sempoux CL, Picard C, Starkel P \& Horsmans YL 2006 Defective hepatic regeneration after partial hepatectomy in leptin-deficient mice is not rescued by exogenous leptin. Laboratory Investigation 86 1161-1171.

Liberzon A, Subramanian A, Pinchback R, Thorvaldsdottir H, Tamayo P \& Mesirov JP 2011 Molecular signatures database (MSigDB) 3.0. Bioinformatics 27 1739-1740. (doi:10.1093/bioinformatics/btr260)

Luo W, Friedman MS, Shedden K, Hankenson KD \& Woolf PJ 2009 GAGE: generally applicable gene set enrichment for pathway analysis. $B M C$ Bioinformatics 10 161. (doi:10.1186/1471-2105-10-161)

Malhi H, Gores GJ \& Lemasters JJ 2006 Apoptosis and necrosis in the liver: a tale of two deaths? Hepatology 43 S31-S44. (doi:10.1002/hep.21062)

National Cancer Institute 2010 NCI-60 cell lines: Gene expression profiles from the NCI 60 data set downloaded from the Developmental Therapeutics Program web site (http://dtp.nci.nih.gov/mtargets/ download.html).

Neuschwander-Tetri BA \& Caldwell SH 2003 Nonalcoholic steatohepatitis: summary of an AASLD Single Topic Conference. Hepatology 37 1202-1219. (doi:10.1053/jhep.2003.50193)

Pereira M Jr, Vidotti DB, Borra RC, Simoes Mde J, Da Silva ID \& Haidar MA 2011 Involvement of GDF-9, leptin, and IGF1 receptors associated with adipose tissue transplantation on fertility restoration in obese anovulatory mice. Gynecological Endocrinology 27 759-766. (doi:10.3109/09513590.2010.534330)

Pessayre D 2007 Role of mitochondria in non-alcoholic fatty liver disease. Journal of Gastroenterology and Hepatology 22 (Suppl 1) S20-S27. (doi:10.1111/j.1440-1746.2006.04640.x)

Ramaswamy S, Tamayo P, Rifkin R, Mukherjee S, Yeang CH, Angelo M, Ladd C, Reich M, Latulippe E, Mesirov JP et al. 2001 Multiclass cancer diagnosis using tumor gene expression signatures. PNAS 98 15149-15154. (doi:10.1073/pnas.211566398)

Rosmarin AG, Resendes KK, Yang Z, McMillan JN \& Fleming SL 2004 GA-binding protein transcription factor: a review of GABP as an integrator of intracellular signaling and protein-protein interactions. Blood Cells, Molecules \& Diseases 32 143-154. (doi:10.1016/j.bcmd.2003. 09.005)

Rytka JM, Wueest S, Schoenle EJ \& Konrad D 2011 The portal theory supported by venous drainage-selective fat transplantation. Diabetes $\mathbf{6 0}$ 56-63. (doi:10.2337/db10-0697)

Sanyal AJ 2002 AGA technical review on nonalcoholic fatty liver disease. Gastroenterology 123 1705-1725. (doi:10.1053/gast.2002.36572)

Sennello JA, Fayad R, Pini M, Gove ME \& Fantuzzi G 2006 Transplantation of wild-type white adipose tissue normalizes metabolic, immune and inflammatory alterations in leptin-deficient ob/ob mice. Cytokine $\mathbf{3 6}$ 261-266. (doi:10.1016/j.cyto.2007.02.001)

Sharma A, Bartell SM, Baile CA, Chen B, Podolsky RH, McIndoe RA \& She JX 2010 Hepatic gene expression profiling reveals key pathways involved in leptin-mediated weight loss in ob/ob mice. PLOS ONE 5 e12147. (doi:10.1371/journal.pone.0012147)

Simha V, Subramanyam L, Szczepaniak L, Quittner C, Adams-Huet B, Snell P \& Garg A 2012 Comparison of efficacy and safety of leptin replacement therapy in moderately and severely hypoleptinemic patients with familial partial lipodystrophy of the Dunnigan variety. Journal of Clinical Endocrinology and Metabolism 97 785-792. (doi:10.1210/jc.2011-2229)

Smyth GK 2005 Limma: linear models for microarray data. In Bioinformatics and Computational Biology Solutions Using $R$ and Bioconductor, 1 edn, pp 397-420. Eds R Gentleman, V Carey, S Dudoit, R Irizarry \& W Huber. New York: Springer.

Stratowa C 2011 Package "xps" - Processing and Analysis of Affymetrix Oligonucleotide Arrays including Exon Arrays, Whole Genome Arrays and Plate Arrays. R package version 1.14.0. In: Bioconductor Software Packages 2011.

Su AI, Welsh JB, Sapinoso LM, Kern SG, Dimitrov P, Lapp H, Schultz PG, Powell SM, Moskaluk CA, Frierson HF Jr et al. 2001 Molecular classification of human carcinomas by use of gene expression signatures. Cancer Research 61 7388-7393. (doi:10.1038/labinvest. 3700474)

Su AI, Wiltshire T, Batalov S, Lapp H, Ching KA, Block D, Zhang J, Soden R, Hayakawa M, Kreiman G et al. 2004 A gene atlas of the mouse and human protein-encoding transcriptomes. PNAS 101 6062-6067. (doi:10.1073/pnas.0400782101)

Subramanian A, Tamayo P, Mootha VK, Mukherjee S, Ebert BL, Gillette MA, Paulovich A, Pomeroy SL, Golub TR, Lander ES et al. 2005 Gene set enrichment analysis: a knowledge-based approach for interpreting genome-wide expression profiles. PNAS 102 15545-15550. (doi:10.1073/pnas.0506580102)

Tilg H \& Moschen AR 2010 Evolution of inflammation in nonalcoholic fatty liver disease: the multiple parallel hits hypothesis. Hepatology $\mathbf{5 2}$ 1836-1846. (doi:10.1002/hep.24001)

Tirindelli R, Dibattista M, Pifferi S \& Menini A 2009 From pheromones to behavior. Physiological Reviews 89 921-956. (doi:10.1152/physrev. 00037.2008)

Tran TT, Yamamoto Y, Gesta S \& Kahn CR 2008 Beneficial effects of subcutaneous fat transplantation on metabolism. Cell Metabolism $\mathbf{7}$ 410-420. (doi:10.1016/j.cmet.2008.04.004)

Wang XW, Heegaard NH \& Orum H 2012 MicroRNAs in liver disease. Gastroenterology 142 1431-1443. (doi:10.1053/j.gastro.2012.04.007)

Wheatcroft SB, Kearney MT, Shah AM, Ezzat VA, Miell JR, Modo M, Williams SC, Cawthorn WP, Medina-Gomez G, Vidal-Puig A et al. 2007 IGF-binding protein-2 protects against the development of obesity and insulin resistance. Diabetes 56 285-294. (doi:10.2337/ db06-0436)

Wong VW, Wong GL, Choi PC, Chan AW, Li MK, Chan HY, Chim AM, Yu J, Sung JJ \& Chan HL 2010 Disease progression of non-alcoholic fatty liver disease: a prospective study with paired liver biopsies at 3 years. Gut $\mathbf{5 9}$ 969-974. (doi:10.1136/gut.2009.205088)

Xie X, Lu J, Kulbokas EJ, Golub TR, Mootha V, Lindblad-Toh K, Lander ES \& Kellis M 2005 Systematic discovery of regulatory motifs in human promoters and $3^{\prime}$ UTRs by comparison of several mammals. Nature $\mathbf{4 3 4}$ 338-345. (doi:10.1038/nature03441)

Yanovski SZ \& Yanovski JA 2011 Obesity prevalence in the United States up, down, or sideways? New England Journal of Medicine 364 987-989. (doi:10.1056/NEJMp1009229)

Yilmaz Y 2012 Review article: is non-alcoholic fatty liver disease a spectrum, or are steatosis and non-alcoholic steatohepatitis distinct conditions? Alimentary Pharmacology \& Therapeutics 36 815-823. (doi:10.1111/j.1365-2036.2012.05196.x)

Zhang YK, Wu KC, Liu J \& Klaassen CD 2012 Nrf2 deficiency improves glucose tolerance in mice fed a high-fat diet. Toxicology and Applied Pharmacology 264 305-314. (doi:10.1016/j.taap.2012.09.014)

Received in final form 21 May 2013

Accepted 29 May 2013

Accepted Preprint published online 29 May 2013 http://jme.endocrinology-journals.org DOI: 10.1530/JME-13-0072
() 2013 Society for Endocrinology Printed in Great Britain 